\title{
FONTES NO ENSINO DE HISTÓRIA DA EDUCAÇÃO: UMA DISCUSSÃO SOBRE CONSTRUÇÃO DO CONHECIMENTO.
}

\author{
SOURCES IN SCHOOL HISTORY OF EDUCATION: A DISCUSSION ON \\ CONSTRUCTION OF KNOWLEDGE.
}

Hardalla Santos do Valle ${ }^{1}$

\begin{abstract}
RESUMO: O presente artigo tem o objetivo de fomentar uma reflexão acerca do ensino de História da Educação e suas amplas possibilidades, como o uso de fontes históricas, no ensino superior. Nessa perspectiva, apresentamos seguintes inquietudes como norteadoras desse trabalho: Qual a importância da disciplina de História da Educação no ensino superior? As fontes históricas assumem um lugar de destaque nesse cenário em que medida? Quais as possibilidades de aprendizado a partir dessas? Na busca pela aproximação dessas respostas, foram escolhidas as metodologias da pesquisa bibliográfica, que auxilia no conhecimento das variáveis e autenticidade da pesquisa, assim como, a análise de conteúdo, que busca a compreensão dos sentidos expressos em um documento escrito.
\end{abstract}

Palavras-chave: Ensino de História da Educação. Fontes. Ensino Superior.

\begin{abstract}
This article aims to foster a reflection on the teaching of History of Education and its vast possibilities, such as the use of historical sources, in higher education. From this perspective, we present the following concerns and guiding this work: How important is the discipline of History of Education in higher education? What is the role of historical sources in the field of History of Education? What are the possibilities of learning from these? In the search for approximate these responses, the methodologies were chosen from literature, which helps in understanding the variables and authenticity of the research, as well as content analysis, which seeks to understand the meanings expressed in a written document.
\end{abstract}

Keywords: Teaching History Education. Sources. Higher Education.

\footnotetext{
${ }^{1}$ Universidade Federal de Pelotas/ Programa de Pós-Graduação em Educação (PPGE-UFPEL).
} 


\section{Introdução}

O campo da História da Educação parece estar se consolidando no cenário acadêmico brasileiro. A organização de inúmeros grupos de pesquisa, como a Sociedade Brasileira de História da Educação (SBHE) ou o Centro de Estudos e Investigações em História da Educação (CEIHEPPGE-UFPEL), periódicos e eventos que agregam especificamente as pesquisas relativas a essa área oportunizaram, e vem oportunizando, discussões metodológicas acerca do papel do historiador da educação e de suas pesquisas. Dentre os vários pontos discutidos, o uso das fontes é, sem dúvida, um dos mais importantes. Isso porque podemos afirmar que sem as fontes e a escolha da metodologia adequada ao trabalho, dificilmente seria possível atribuir o status científico às pesquisas que objetivam ser de História da Educação.

No que tange o ensino da História da Educação, ainda é preciso investigar e discutir as múltiplas possibilidades de abordagens e o desenvolvimento de sua aprendizagem. A História da Educação é uma disciplina que aborda as mais diversas expressões que compõem o mundo da educação, como aulas, alunos, professores, disciplinas, instituições, material escolar, comportamento, corpo dirigente, regulamentos, estatutos, entre outros. Elementos que, por fazerem parte da vida da maioria dos sujeitos em algum período de suas trajetórias, podem passar despercebidos. Assim sendo, pouco notada a capacidade desses elementos de influenciar e espelhar nossa vida e sociedade. Cumpre considerar, que no contexto atual estimular o conhecimento dos indivíduos sobre a complexidade do universo educacional em suas diversas formas torna-se essencial, tanto para construir saberes, incitar reflexão e criticidade, como alicerçar a luta em prol da edificação de um modelo de educação escolar condizente com as necessidades e os direitos daqueles que dela usufruem.

Nesse sentido, o presente artigo foi construído no intuito de agregar as discussões sobre o ensino de História da educação na acadêmia, focando em algumas opções metodológicas de trabalho, especialmente no uso de fontes em sala de aula. 
Dessa forma, apresentamos seguintes inquietudes como norteadoras desse trabalho: Qual a importância da disciplina de História da Educação no ensino superior? As fontes históricas assumem um lugar de destaque nesse cenário em que medida? Quais as possibilidades de aprendizado a partir dessas?

O meio escolhido de nos aproximarmos dessas respostas foi, primeiramente, a metodologia da pesquisa bibliográfica, que auxilia na escolha de um método apropriado, conhecimento das variáveis e autenticidade da pesquisa, assim como, a análise de conteúdo, que é um meio de captar o sentido que está por trás da superfície textual de um documento.

Dado o exposto, primeiramente iremos discorrer sobre o campo da História da Educação e sua importância no ensino superior. Logo após, será traçado um panorama sobre o conceito de fonte histórica. Por conseguinte, serão abordados alguns aspectos do processo da utilização de fontes na construção do conhecimento. Assim sendo intuito, instigar a reflexão acerca da relevância do ensino de História da Educação na acadêmia e disseminar suas possibilidades na construção da aprendizagem, como o uso de fontes históricas.

\section{A Disciplina de História da Educação e sua importância no Ensino Superior.}

A história da educação é um campo do saber capaz de proporcionar uma compreensão simultânea das descontinuidades de cada tempo e das permanências e sobrevivências. Isso porque é uma construção de relações, de interações complexas no tempo e no espaço e uma superação das oposições: presente/passado; individual/social; sistemas formais/sistemas informais e teoria/prática (MAGALHÃES, 1999, p. 49). Em outras palavras, é um campo do saber de informação e relativização que permite compreender, explicar e avaliar em que medida as ideias pedagógicas e as 
práticas educativas, de diferentes tempos e espaços, são elementos importantes de uma construção social.

\begin{abstract}
Nesse âmbito, o historiador da educação coloca-se num plano existencial e assume-se como um mediador, porque questionador "lúcido", entre o passado e o futuro. Deste modo não apenas o trabalho do historiador tem vindo a reforçar-se, nomeadamente, pela abertura à interdisciplinaridade, como tem vindo a dignificar-se. Analisando e explicando a gestação processual da mudança, por contraposição /transposição da continuidade; questionando /inventando esta última, em si e por oposição àquela. O sentido da História é lhe deste modo conferido, em boa parte, por aquilo que ela própria (produz), contrapondo lógicas dedutivas e lógicas indutivas, diferenciando e contrapondo avanços e bloqueios (revisionismo); superando lógicas historiográficas simplistas de produção/reprodução; caos/revolta, por lógicas historiográficas completas, interativas, construtivistas (MAGALHÃES, 1999, p. 50).
\end{abstract}

Como podemos perceber na citação, na opinião do autor, o papel do historiador da educação não se reduz a análises simplificadas, ou revisionistas, mas pauta-se sobre a compreensão do contexto e seus elementos representativos, utilizando-se para isso muitas vezes da interdisciplinaridade para o desenrolar da trajetória discutida e o estabelecimento de uma nova teia de significados. Dessa maneira, se faz interessante estimar, discutir e refletir acerca dos trabalhos produzidos a partir das realidades e dos contextos educacionais, visto que, a compreensão histórica dos fenômenos educativos está intrinsecamente associada a outros fenômenos políticos, culturais, econômicos e sociais. É importante salientar que esse campo não é importante apenas porque nos fornece a memória dos percursos educacionais, mas, sobretudo porque nos permite compreender que não há nenhum determinismo na evolução dos sistemas educativos, das idéias pedagógicas ou das práticas escolares, pois tudo é produto de uma construção social.

$\mathrm{Na}$ perspectiva do ensino, a disciplina de História da Educação permite a análise dos sujeitos e processos educativos no tempo e espaço, originando a reflexão sobre um mundo no qual professores e alunos, ainda que imersos, muitas vezes não percebem todos os significados que o 
compõem. Através desse encontro com o "outro" no tempo e espaço tornase possível, por similitudes e diferenças, uma maior compreensão de si próprio, sua sociedade e cultura. Com efeito, a História da Educação permite o entendimento que em outros lugares e épocas a educação, e a escola em particular, sofreram modificações, mas parecem manter alguns elementos intocados, que surpreendentemente ainda hoje fazem parte do nosso contexto. Dessa forma, também ajudando-nos a olhar a realidade com paciência e criticidade, posto que, muitas vezes foi preciso duas ou três gerações para que uma inovação educacional se concretizasse (LOPES, 2005).

Em relação ao nascimento da História da Educação enquanto disciplina, destacamos que essa se constituiu principalmente nas Escolas Normais e cursos de formação de professores. Sua trajetória está relacionada à área da Pedagogia que, desde o século XVIII começa a se desenvolver em alguns países da Europa e Estados Unidos. No Brasil a história dessa disciplina também está associada ao desenvolvimento das escolas normais e, posteriormente, dos cursos de Pedagogia das faculdades de Filosofia, portanto ligada ao campo da educação e principalmente ao ensino. No Brasil dos dias atuais a História da Educação é ministrada principalmente no Ensino Superior, constantemente para os cursos de Pedagogia e de modo incipiente para as demais licenciaturas (BORGES, 2011).

Logo, mesmo com uma relevante trajetória a disciplina de História da Educação ainda pode ser descrita como embrionária na composição dos quadros de disciplinas das universidades. Tal panorama precisa ser modificado, pois se entende que o ensino superior se constitui em um processo de estimulação da criação cultural, do desenvolvimento do espírito científico e pensamento reflexivo (BRASIL, LDB, art.43, 1996). Portanto, torna-se necessário na composição dos currículos disciplinas que agreguem na condução a uma progressiva autonomia do aluno, busca de conhecimentos, bem como, ao desenvolvimento da capacidade de reflexão. Nessa perspectiva, a História da Educação surge como um campo no qual os processos educativos e a sociedade como um todo são constantemente 
pensados e discutidos, de modo a inquietar, desconstruir ideias préconcebidas, e incentivar a autocrítica e ânsia por mudanças. Dessa forma, suscitando o desejo permanente de aperfeiçoamento cultural e profissional através de uma integração dos conhecimentos que vão sendo adquiridos numa estrutura intelectual sistematizadora das diferentes especificidades educativas de cada geração.

\section{Fontes}

Fonte é uma palavra que apresenta, via de regra, duas conotações. Por um lado, significa o ponto de origem, o lugar de onde brota algo que se projeta e se desenvolve indefinidamente e inesgotavelmente. Por outro lado, indica a base, o ponto de apoio, o repositório dos elementos que definem os fenômenos cujas características se busca compreender. Ademais, a palavra fonte também pode se referir a algo que brota espontaneamente, naturalmente, e a algo que é construído artificialmente (SAVIANI, 2006).

Cumpre esclarecer que as fontes estão na origem, constituem o ponto de partida, a base, o ponto de apoio da construção historiográfica que é a reconstrução, no plano do conhecimento, do objeto histórico estudado. As fontes históricas não são a fonte da História, ou seja, não é delas que brota e flui a História. Elas, enquanto registros, testemunhos dos atos históricos, são a fonte do nosso conhecimento histórico. Isto é, delas que brota; nelas que se apoia o conhecimento que produzimos a respeito da História (SAVIANI, 2006).

Entre as fontes naturais utilizadas em pesquisas históricas, podemos mencionar o habitat de animais, lugares de preservação ecológica, espaços verdes e fósseis. Já entre fontes construídas pelo homem, podemos elencar documentos oficiais, jornais, entrevistas, fotografias, construções arquitetônicas, objetos, entre outros.

As fontes produzidas pelo homem são repletas de intencionalidades, que no ato da pesquisa devem ser percebidas e analisadas. Documento 
algum é neutro, e sempre carrega consigo a opinião da pessoa e/ou órgão que o escreveu. Uma carta pastoral de um bispo, por exemplo, é a opinião do próprio autor, mas profundamente inserido em um panorama ideológico da Igreja daquele momento e local. A interação do bispo com sua comunidade e com os outros membros do clero dará um tom específico a essa carta, e deve ser considerada (BACELLAR, 2010).

Por consequência, isso conduz a um trabalho de pesquisa não só das peças textuais em si, mas também do momento histórico em que foi produzido o documento. É preciso conhecer a fundo, ou pelo menos da melhor maneira possível, a história da peça documental que se tem em mãos para compreender sob quais condições o documento foi escrito, com que propósito e para quem. Em outras palavras, contextualizar o documento que se usa é fundamental para o oficio do historiador.

Fontes orais, como entrevistas, também não fogem a regra. São fontes que permitem o registro de testemunhos e o acesso a "histórias dentro da história", ampliando as possibilidades de interpretação do passado. No ato de análise devemos considerar as condições de produção da fonte oral e estudar exaustivamente o assunto abordado, a fim de conseguir utilizar a entrevista como resíduo de ação, além de relato. (ALBERTI, 2010).

No que tange a fontes materiais, como construções arquitetônicas e objetos, essas podem ser descritas como símbolos do passado que expressam um conjunto de informações a partir dos mais singelos detalhes. Estão relacionadas com a finalidade ou sentido que os objetos têm para um povo numa cultura, ou seja, com a importância e influência que exercem na definição da identidade cultural de uma sociedade. O que é material e físico é entendido como um legado, algo para ser apreendido, usado e preservado, que ensina a reproduzir o mesmo objeto ou a guardar a sua memória. Trabalho rico e minucioso, seu principal desafio consiste na busca por ferramentas interpretativas.

Quando consideramos o proposto, referente às fontes para pesquisas relativas à História da Educação, podemos considerar obvio que a escolha dessas dependerá não apenas do objeto e dos objetivos da pesquisa, mas 
também da delimitação, isto é, dos recortes efetuados. Um espaço de educação, seja escolar, tribal, religioso ou familiar é influenciado- direta ou indiretamente- por sujeitos, instituições, economia, politica, cultura e etc.. O enfoque de estudo dependerá do delineamento da pesquisa.

Constantemente pesquisadores que se dedicam ao estudo da trajetória profissional de um determinado educador, história de uma Instituição ou outras perspectivas do século $X X$, utilizam-se enfaticamente de fontes orais em paralelo a fontes oficiais, biográficas e materiais. Já aqueles que objetivam estudar a aspectos da educação do período colonial ou século XIX possuem como principal fonte documentos oficiais, ao lado de fontes materiais e impressos. A grande realidade é que o historiador da educação depende das fontes existentes relativas ao objeto escolhido, seu número e acessibilidade para o desenvolvimento da pesquisa. Nesse sentido é compreensível que dificilmente alguém que pesquise sobre período colonial e século XIX não utilize fontes orais, visto o grande passar dos anos e a inexistência nessas épocas de aparelhos de gravação que permitissem a perpetuação de relatos. Em contraponto pesquisadores que focam no século $X X$, possuem muitos personagens da sua história dispostos a contar suas visões sobre os fatos, o que possibilita e instiga a construção de memórias, já que o acervo documental é de menor monta.

\section{O uso de fontes históricas em sala de aula.}

Quando observamos a organização do tempo e das informações históricas em um livro, pensamos sobre todo o processo que envolveu a fabricação daquele material disponível para estudo. Choppin (2009) ressalta que os livros representam produtos de grupos da sociedade, os quais procuram perpetuar suas identidades, valores e preceitos num foco cultural.

[...] é, antes de tudo, uma mercadoria, um produto do mundo da edição que obedece à evolução das técnicas de fabricação e comercialização pertencentes à lógica do mercado. Como 
mercadoria ele sofre interferências variadas em seu processo de fabricação e comercialização. Em sua construção interferem vários personagens, iniciando pela figura do editor, passando pelo autor e pelos técnicos especializados dos processos gráficos, como programadores visuais, ilustradores. (BITTENCOURT, 2009, p. 71)

A partir das ideias expressas na citação, podemos afirmar que, apesar ser uma ferramenta indispensável no processo de ensino universitário, é preciso possuir uma visão crítica sobre o livro. Haja vista que, o passado, enquanto objeto de estudo, não está devidamente organizado e analisado em todas as suas dimensões. Logo, para que seja possível conhecê-lo, o professor da área da História da Educação precisa sair em busca dos vestígios que possam fornecer cada vez mais informações e respostas ao seu exercício de investigação e construção do conhecimento.

No cotidiano da sala de aula é necessário substituir o ensino que se limita a transmissão de conteúdos por um ensino que constitui processo de investigação do conhecimento. Uma boa forma de atingir esse objetivo é a pesquisa. No entanto, se deve considerar o processo de ensinar/aprender como atividade integrada a essa pesquisa, assim criando e recriando situações de aprendizagem.

Nessa perspectiva, o uso de fontes históricas em sala de aula é uma possibilidade que deve ser apreciada e valorizada. A riqueza de informações que podemos extrair das fontes justifica o seu uso no fazer pedagógico de várias áreas das Ciências Humanas e Sociais porque possibilita ampliar o entendimento de objetos cuja compreensão necessita de contextualização histórica e sociocultural.

Outra justificativa para o uso de fontes, como documentos, em sala de aula é o fato que ela permite acrescentar a dimensão do tempo à compreensão do social. Assim favorecendo a observação do processo de maturação ou de evolução de indivíduos, grupos, conceitos, conhecimentos, comportamentos, mentalidades, práticas, entre outros. (CELLARD, 2008).

Sob tal aspecto, notamos que o docente de História da Educação deve estar à procura constante e regular de fontes que viabilizem o seu 
contato com as experiências que já se consumaram ao longo do tempo. Fora desse tipo de ação, sua aula fica sujeita à produção de suposições e julgamentos que fogem ao compromisso do historiador em conferir voz ao tempo que ele observa e pesquisa. Logo, as fontes históricas aparecem como elementos de suma importância em tal caminhada.

Em contraposição ao que possa parecer, o reconhecimento de fontes históricas não é naturalmente realizado por aqueles que se colocam em busca do passado. Ao estudar, analisar e elaborar seus planos de aula, o professor da área da História da Educação, dispõe atualmente de diversos instrumentos metodológicos. O direcionamento do tipo de aula que será empreendida dependerá de fatores como a natureza da turma, o conteúdo abordado e a corrente de pensamento que guia o professor. Dependendo dos interesses e influências que marcam a trajetória do professor, notamos que as fontes históricas podem ser empregadas ou não em seu trabalho.

Não podemos deixar de frisar que o uso de diferentes fontes acarretou o reconhecimento de novos desafios ao ofício do professor. Em contrapartida, ofereceu a esse, e também aos discentes, a oportunidade de renovar e determinar o crescimento da produção técnica, científica e didática sobre o assunto.

A mediação aqui discutida do professor se dá quando ele escolhe em um conjunto de dados, uma fonte específica e através dela apresenta a história, instigando a construção do conhecimento e a critica livre do aluno. As novas concepções pedagógicas paralelas aos novos aportes teóricos e metodológicos da história legitimam o uso das fontes, não apenas como suporte informativo, mas sim como todo um conjunto de signos, visual, textual, produzido numa perspectiva diferente da comunicação de um saber disciplinar, mas utilizando essas como fins didáticos. Nesse sentido, concordamos com Gramsci (1978) quando aponta que é necessário o ensino possuir o fascínio das coisas vitais e respeitar a curiosidade que interroga no incansável movimento de busca e recomeço.

O trabalho do professor da História da Educação tem início com o planejamento pedagógico, quando seleciona seus conteúdos, prioriza a construção de conceitos, a análise do contexto temporal, a aplicação de 
categorias e o emprego específico de vocábulos. Mas, principalmente quando faz a opção pela criatividade em sala de aula, experimentando novas metodologias e utilizando diversos recursos pedagógicos.

Um professor com essa vertente problematiza o ensino, entrelaçando questões do universo acadêmico e da vivencia de seus alunos. Assim fazendo com que o conteúdo, que parece tão distante da realidade discente, adquira significados (FONSECA, 2003). Com efeito, especialmente, orienta seus alunos a construírem o sentido da história através da observação, descrição, comparação e análise das fontes. Grande sustentáculo da construção histórica.

Além disso, é de extrema importância a escolha por um procedimento pedagógico capaz de conduzir os discentes a superação da asserção errônea construída no passado da fonte enquanto prova da verdade, ou do acontecido. Logo, é indispensável esclarecer aos alunos que toda fonte é um fragmento de memória, um vestígio de um tempo vivido, indícios de situações e/ou representação de uma época.

Tendo esclarecidos esses aspectos, destaca-se como exemplo de fonte que pode ser utilizada em aula a imprensa, por ser uma fonte histórica acessível e de grande valor. Deve-se considerar que a produção da imprensa escrita ainda é uma prática altamente disseminada nos dias atuais. Fato que, através de diálogos sobre as especificidades dos jornais de hoje, permite estabelecer uma fácil compreensão sobre essa fonte. Ademais, não podemos deixar de mencionar que o uso da imprensa escrita do passado nas aulas fomenta um novo olhar dos discentes sobre a atual, fazendo-os observar de maneira crítica seus jornais cotidianos e as informações disseminadas. Outra possibilidade é a proposta de entrevistas com familiares de mais idade sobre a educação em determinados períodos. Assim instigando a preservação da memória, através da história oral, e elucidando a proximidade da História da Educação com os sujeitos. 


\section{Considerações}

Por tudo que foi apresentado, podemos afirmar que a disciplina de História da Educação é importante no contexto do ensino superior porque estabelece um espaço no currículo para a compreensão e reflexão dos processos educacionais por uma perspectiva ampla e historicamente embasada. Assim instigando o olhar critico dos alunos, a curiosidade histórica e ânsia por mudanças.

Nesse campo do saber as fontes constituem, enquanto registros e testemunhos dos fatos, a principal ferramenta na construção do conhecimento histórico. Já quando utilizadas na sala de aula, de maneira correta e pertinente, podem ser extremamente agregadoras na construção do aprendizado. Isso porque seu papel não se limita apenas a compreensão da noção de tempo, mas é também um meio de instigar a compreensão da complexa teia de significados que faz parte da História da Educação.

Nessa perspectiva, apresentamos na elaboração de nosso trabalho, primeiramente uma discussão sobre a História da Educação explorando seu conceito e definindo-a como um campo de informação e relativização que permite compreender, explicar e avaliar em que medida as ideias pedagógicas e as práticas educativas são elementos importantes na construção social. Em seguida destacamos o nascimento da História da Educação como disciplina, associada a formação de professores, e sua atual situação no ensino superior dentro da educação brasileira. Quanto ao ensino, destacamos que essa disciplina possibilita a análise dos processos educativos, estimulando o desenvolvimento do espírito científico, conhecimento cultural e o pensamento reflexivo.

Em relação às fontes discorremos a respeito de sua dupla função, origem e base e definimo-las não como fonte da História, mas como fonte do conhecimento histórico. Logo após, elencamos os principais tipos e suas características, relacionando posteriormente com pesquisas relativas ao âmbito da História da Educação. Desse modo, constatamos que o historiador da educação depende das fontes existentes relativas ao objeto 
escolhido, seu número e acessibilidade para o desenvolvimento da pesquisa.

$\mathrm{Na}$ questão da utilização de fontes em sala de aula, ressaltamos que é necessário instigar a curiosidade, o interesse e a inquietação dos discentes acerca do conhecimento proposto. A atuação do professor de História da Educação inicia a partir do planejamento pedagógico, por meio da seleção do conteúdo, que ganha força quando realizado de forma a associada ao trabalho com fontes históricas. Logo, o papel das fontes dentro do ensino de História da Educação é o de fomentar a construção dos saberes. Nesse sentido, destacamos como exemplo de fontes a imprensa e história oral, por sua proximidade com o mundo do discente e pelo olhar crítico que suas utilizações podem proporcionar frente a realidade atual.

Por fim, enfatizamos que as fontes históricas, no processo de construção do conhecimento podem ser agregadoras se usadas como sustentáculo de uma proposta de educação bem embasada e criativa. A prática de instigar o interesse dos discentes e mediar o conhecimento por meio de recursos como as fontes representa um grande desafio, mas também uma imensa possibilidade, que deve ser considerada na busca pela qualidade, valorização, e maior inserção nos currículos do ensino da disciplina de História da Educação.

\section{Referências}

ALBERTI, V. Histórias dentro da História. In: PINSKY, C. B. (Org.). Fontes Históricas. São Paulo: Contexto, 2010.

BACELLAR, C. Uso e mau uso dos arquivos. In: PINSKY, C. B. (Org.). Fontes Históricas. São Paulo: Contexto, 2010.

BITTENCOURT, C. Livros didáticos entre textos e imagens. O saber histórico na sala de aula. São Paulo: Contexto, 2009.

BORGES, B. G.; GATTI JÚNIOR, D. Ensino de História da Educação na formação de professores no Brasil atual. Anais do XXVI Simpósio Nacional de História - ANPUH. São Paulo, 2011. Disponível em:

http://www.histedbr.fae.unicamp.br/revista/edicoes/40/art02_40.pdf

BRASIL. LDB-Lei de Diretrizes e Bases da Educação Nacional- lei no 9.394, de 20 de dezembro de 1996. Brasília: Câmara dos Deputados, 
Coordenação Edições Câmara, 2010. Disponível em:

http://bd.camara.gov.br/bd/bitstream/handle/bdcamara/2762/ldb_5ed.pdf

CELLARD, A. A análise documental. In: POUPART, J. A pesquisa qualitativa: enfoques epistemológicos e metodológicos. Petrópolis: Vozes, 2008.

CHOPPIN, A. O manual escolar: uma falsa evidência histórica. Revista História da Educação, ASPHE/FaE/UFPel. v. 13, Jan/Abr 2009. Disponível em: http//fae.ufpel.edu.br/asphe

FONSECA, S. G. Didática e prática de ensino de História. Campinas, São Paulo: Papirus, 2003.

GRAMSCI, A. Concepção dialética da História. Rio de Janeiro: Civilização Brasileira, 1978.

LOPES, E. M. T. e GALVÃO, A. M. História da Educação: O que você precisa saber sobre. Rio de Janeiro: DP\&A, 2005.

MAGALHÃES, J. P. Linha de investigação em História da Educação e da alfabetização em Portugal-Um domínio do conhecimento em renovação. In: SAVIANI, D. ; SANFELICE, J. L.; LOMBARDI, J. C. (Org.). História da Educação: perspectivas para um intercâmbio internacional. Campinas: Histedbr, 1999.

SAVIANI, D. Breves considerações sobre fontes para a História da Educação. Revista HISTEDBR On-line, Campinas, n. especial, 2006. Disponível em:

http://www.histedbr.fae.unicamp.br/revista/edicoes/22e/art5_22e.pdf

Enviado em 16 de Junho de 2012. Aprovado em 02 de Setembro 2012. 